\title{
Developing Dermal Policy Based on Laboratory and Field Studies
}

\author{
A new National Institute for Occupational Safety and Health \\ (NIOSH) research program in response to the National \\ Occupational Research Agenda (NORA)
}

\section{Overview}

Estimates indicate that more than 13 million workers in the United States are potentially exposed to chemicals that can be absorbed through the skin. A worker's skin may be exposed to hazardous chemicals through direct contact with contaminated surfaces, deposition of aerosols, immersion, or splashes. When substantial amounts of chemicals are absorbed, systemic toxicity can result. Contact dermatitis can also result when chemicals are absorbed through a worker's skin. Contact dermatitis is one of the most common chemically induced causes of occupational illness, accounting for 10 to 15 percent of all occupational illnesses at an estimated annual cost of at least $\$ 1$ billion.

The National Institute for Occupational Safety and Health (NIOSH) and approximately 500 external partners created the National Occupational Research Agenda (NORA) to guide occupational safety and health research into the next decade. The Agenda is made up of 21 priority research areas including allergic and irritant dermatitis. As part of NORA, NIOSH encouraged its intramural researchers to join together to develop large scale programs in and across NORA priority areas. One of the three funded interdisciplinary cross-divisional programs is the development of a dermal policy based on laboratory and field studies. The overall goal of this program is to promote the development of improved NIOSH policies and recommendations for identifying and controlling dermal overexposures and dermatitis. This goal will be accomplished by (1) adding critical information to our current knowledge base through laboratory and field investigations and (2) developing and applying scientific decision-making processes for policy development using that knowledge base.

continued on the back
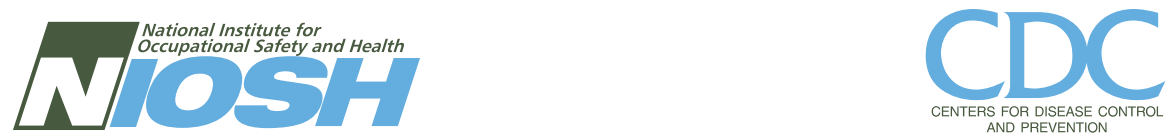


\section{Current Projects}

Project 1 Developing Decision-Making
Procedures and Documents

Project 2 Biomonitoring Analyses for Studies of Dermal Exposures

Project 3 Field Studies to Assess and Prevent Dermal Overexposures

Project 4 Developing an Engineering Control Knowledge Base

Project 5 Developing and Demonstrating the Use of Colorimetric Indicators

Project 6 Controlling Dermal Chemical Exposure Using Personal Protective Clothing

Project 7 Developing Healthy and Dermatitis Skin Absorption Models

Project 8 Quantitative Structure Activity Relationship Modeling

The two Core Projects provide coordination and a capability to identify chemicals that may irritate or sensitize workers.
For additional information, contact:

Sid Soderholm, Ph.D.

Director, Dermal Exposure Research Program

Chief, Exposure Assessment Branch

NIOSH, MS 3030

1095 Willowdale Road

Morgantown, WV 26505-2888

Phone: 304-285-6034

E-mail: Ssoderholm@cdc.gov

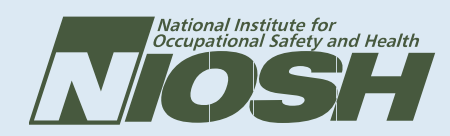

Delivering on the Nation's promise: safety and health at work for all people through research and prevention

For more information about NORA, contact NIOSH at

1-800-35-NIOSH (1-800-356-4674)

or visit the NIOSH Web site at www.cdc.gov/niosh/norahmpg.html

DHHS (NIOSH) Publication No. 2000-142

\section{NORA}

National Institute for Occupational Safety and Heatlh

Education and Information Division

4676 Columbia Parkway

Cincinnati, OH 45226-1998 